\title{
Child Maltreatment Prevention in the Philippines: A Situationer
}

\author{
Bernadette J. Madrid, ${ }^{1,2}$ Laurie S. Ramiro, ${ }^{3}$ Sandra S. Hernandez, ${ }^{1}$ John J. Go ${ }^{4}$ and Juanita A. Basilio ${ }^{5}$ \\ ${ }^{1}$ Child Protection Unit, Department of Pediatrics, College of Medicine and Philippine General Hospital, University of the Philippines Manila \\ ${ }^{2}$ Child Protection Network Foundation, Inc. \\ ${ }^{3}$ Department of Behavioral Sciences, University of the Philippines Manila \\ ${ }^{4}$ National Professional Officer, Non-communicable Diseases, World Health Organization, Philippines \\ ${ }^{5}$ Department of Health, Philippines
}

\begin{abstract}
Objectives. The study aims to gather information regarding the situation of child maltreatment as well as relevant primary prevention policies, programs and resources in the Philippines. With decentralized governance, how local communities implement their child maltreatment prevention programs will also be looked into.
\end{abstract}

Methods. Key informant interviews with national policy makers and program managers were conducted. Stakeholders from three local government units were also interviewed. Relevant secondary documents were reviewed.

Results. The Philippines has a good number of laws, policies and programs on child protection, albeit with limited funds and trained personnel. A number of these laws and policies impact on the prevention of child maltreatment although very few are directly related to primary prevention. There was a disparity between what is required by national laws and policies; and actual implementation of programs on child protection. With the devolution of health and social services, implementation and support for programs depended on the interests and priorities of local executives. This is further compounded by the fact that there is no reliable data on child maltreatment in the country.

Conclusion. Recommendations include conducting a national prevalence study on child maltreatment; working with communities to increase their readiness and capacity to implement a primary prevention program on child maltreatment, and identifying a central body with the legal mandate to implement the national plan to end violence against children.

Key Words: child maltreatment, prevention policies, primary prevention programs, Philippines

Corresponding author: Bernadette J. Madrid, MD

Child Protection Unit

Department of Pediatrics

Philippine General Hospital

University of the Philippines Manila

Taft Avenue, Ermita, Manila 1000 Philippines

Telephone: +6325268418

Fax No: +632 4043955

Email: madridbernie@gmail.com

\section{Introduction}

The 2002 World Health Organization Report on Violence and Health cites studies that report high rates of child abuse and neglect in all regions of the world. In the Philippines, estimates from 2000 suggest that 1.8 million children were into prostitution and pornography while 1.2 million were victims of human trafficking. ${ }^{1}$ A baseline national survey in 2000 also revealed that $86.6 \%$ of male adolescents and $85.2 \%$ of female adolescents have experienced adult-inflicted abusive behaviors at least once in their lifetime. ${ }^{2}$ While they were growing up, $83 \%$ reported to have experienced physical maltreatment while $59.7 \%$ claimed to have been psychologically abused. About $12 \%$ were sexually molested and $1.8 \%$ experienced forced sex or rape. The 2011 Survey on Children revealed that $18.9 \%$ of Filipino children aged 5-17 years were working. ${ }^{3}$ Of the 5.49 million working children, 3.03 million were considered as Child Labour and 2.99 million as Hazardous Child Labour. Data at the Child Protection Unit of the Philippine General Hospital also indicate increasing number of child abuse cases where $70 \%$ were sexual and $22 \%$ were physical in nature. ${ }^{4}$ Despite these statistics, much violence against children remains hidden or goes unreported.

Experts have repeatedly stressed the preventability of child maltreatment. Focusing on primary prevention, the World Report on Violence and Health ${ }^{5}$ asserted that violence is preventable and that public health has an important role in addressing its causes and consequences. In his report for the United Nations Study on Violence against Children, Pinheiro recommended prioritization of prevention by allocating resources to address risk factors and preventing violence before it occurs. ${ }^{6}$

Three levels of preventive services are usually offered to children, their families and communities in general (Figure 1). ${ }^{7}$

Primary prevention activities (universal approach) attempt to stop maltreatment before it occurs and target the general population. These activities aim to raise awareness among the general public, service providers, and decision-makers about the nature and consequences of child maltreatment. Secondary prevention activities (selected/targeted approach) focus on high-risk individuals and groups, or those who have one or more risk factors 
associated with child maltreatment. Support groups that help parents deal with everyday stresses and home visiting programs are some examples. Tertiary prevention services are given to individuals or groups where maltreatment has already occurred to reduce the negative effects of maltreatment and to prevent its recurrence.

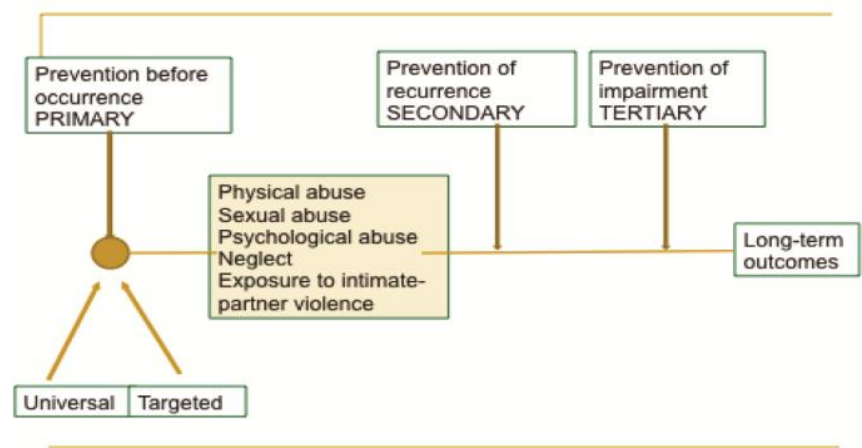

Figure 1. Framework for prevention of child maltreatment and associated impairment. MacMillan, Wathen, et al. Lancet 2009

It is recognized that the most cost-effective way of minimizing the increased risks and losses brought about by child maltreatment is to focus on primary prevention. This approach will definitely reduce the incidence of new cases because problems and situations in the family and community that spawn violence and abuse are "nipped in the bud", so to speak. Activities at the family level, for instance, will assist parents to enhance their potential as good role models to their children. Preventive measures at the community and societal level can ensure that citizens become aware of the need for a good future for children as there is a local saying that states that "the future of a nation depends on children (ang pag-asa ng bayan ay nasa kabataan)". The ultimate goal is to allow the child to grow in a secure, stable and nurturing family and community.

Hence, increased awareness of the problem of child maltreatment requires more effective action. While early intervention as well as crisis intervention and treatment are preventive strategies in child maltreatment, the increasing number of cases calls for an approach that would address the underlying causes thus preventing the problem even before it starts. It is necessary to allocate resources wisely and promote evidence-based interventions that would have a greater impact on preventing child maltreatment. This means not only investigating the effectiveness of current services but investing in programs for the primary prevention of maltreatment. Butchart et al. noted that while the effects of primary prevention strategies may only be seen after a number of years, these same programs are most costeffective, resulting in savings that far exceed their costs. ${ }^{8}$ Recent research in business and economics also support investments in early childhood interventions and preventive services as these result in greater economic, health and social benefits than treating future negative outcomes. ${ }^{9}$

Primary prevention strategies that have been identified thus far include investing in early interventions, increasing positive adult involvement, community-based interventions, changing cultural norms, reducing income inequality, and improvements in the criminal justice and social welfare systems. ${ }^{8}$ However, most of the evidence on the effectiveness of prevention strategies comes from high-income countries with outcome evaluation studies from low- and middleincome countries making up less than $1 \%$ of the evidence base. $^{10}$

In a systematic review of child maltreatment prevention focusing on universal and selective interventions, four of seven types of interventions were promising for preventing actual child maltreatment. These include home-visiting, parent education, abusive head trauma prevention, and multi-component programmes..$^{10}$ Interventions aimed at the individual (child or caregiver) or families are those that have undergone the most rigorous evaluations. A review of recent research evidence for preventing child maltreatment identified programs that have shown benefits for preventing physical abuse and neglect. ${ }^{7}$ For example, the Nurse-Family Partnership, a home visitation program provided by nurses to low-income first-time mothers from prenatal period through infancy, provided the best evidence for reducing child maltreatment with one randomized controlled trial showing a reduction in actual child abuse by 48 percent at 15 year-follow up. Although the rates of child protection reports did not differ between the intervention and control groups, the Early Start Programme, also a home visitation program, reduced the incidence of childhood injuries and hospital admissions for severe child abuse and neglect. Among parent training programs, the Triple P-Positive Parenting Programme has shown positive effects on substantiated cases of child maltreatment, child out-of-home placements and child maltreatment injuries after dissemination of Triple $\mathrm{P}$ professional training of service providers and exposure to universal media and communication strategies. Interventions delivered in health care facility settings, including abusive head trauma education programs and an enhanced model of pediatric care for children at risk, have also shown some promise. For the prevention of child sexual abuse, school-based education programs were able to improve knowledge and protective behaviours, although whether these translated into actual prevention of sexual abuse is still unknown.

Recent public health promotion strategies emphasize the role of organized and empowered communities and capacity building for less developed communities. ${ }^{11}$ Community readiness, the degree to which a community is prepared to take action on an issue, has also been recognized as an essential element and key determinant in the successful development, implementation and sustainability 
of prevention programmes. Community readiness theory acknowledges that efforts are more effective and sustainable when people are involved in decision-making and interventions are culturally appropriate. It recognizes that communities, whether geographic, organizational or issuebased, may be at different stages of readiness and as for individuals, change is a process that communities go through. The Community Readiness Model of the Tri-Ethnic Center for Prevention Research describes nine stages of readiness that range from having no awareness of issues to a high level of community ownership where there is detailed knowledge of the prevalence, causes and consequences of an issue and evaluation mechanisms are in place. ${ }^{12}$

Among the various types of child protection services, tertiary prevention activities are more commonly implemented in the Philippines through the establishment of Child Protection Units and other forms of NGO programs in several communities. Secondary, much more primary prevention activities remain largely ignored. As an initial effort, there is a need to look at the overall situation of primary prevention of child maltreatment programs in the country.

\section{Objectives of the study}

This study aimed to assess the situation of child maltreatment in the Philippines, specifically in relation to the policies and programs on the primary prevention of child abuse and neglect. More specifically, it intends to:

1. Assess the country's efforts with regard to child maltreatment prevention;

2. Know the various prevention activities being implemented by national and local groups and organizations;

3. Review and analyze current policies, programs and strategies on child maltreatment prevention;

4. Recommend a specific course of action to the different government agencies and committees that have the legal mandate to implement a National Action Plan on the Primary Prevention of Child Maltreatment.

\section{Study Framework}

The framework looks at the various prevention resources that are used as important inputs into the establishment and implementation of prevention programs and strategies for child maltreatment in national and local communities. Using an ecological model, how these prevention programs were implemented at the individual, relationship, community and societal levels were analyzed (Figure 2).

\section{Methods}

\section{$\underline{\text { Research design }}$}

This is a descriptive study mainly using a qualitative design.

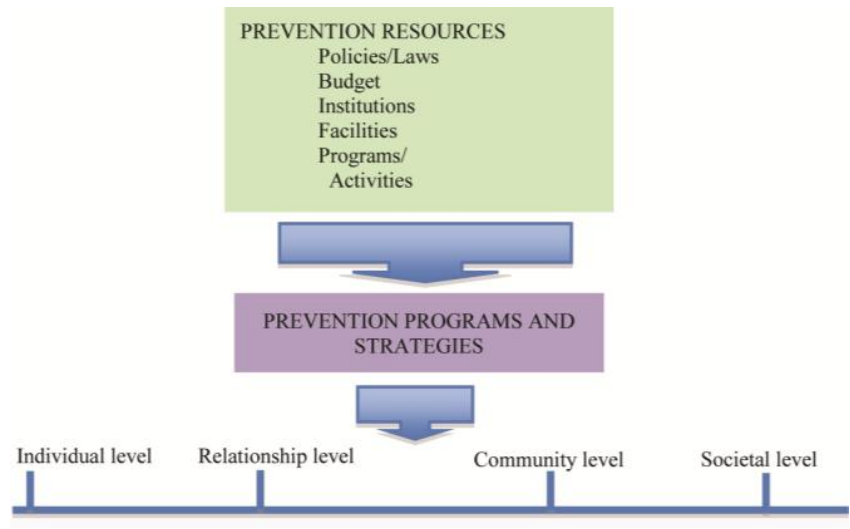

Figure 2. A framework showing the relationship among prevention resources, prevention programs and effects at the individual, relational, community and societal levels.

\section{Study settings}

This study had a national and local coverage. Two urban and one rural barangays (villages) served as local study sites.

\section{Sources of data}

Secondary sources were in the form of inventories of national and local policies and ordinances, past and ongoing prevention programs and activities, research reports, highlevel planning documents, surveillance and other epidemiological data, national and local budgets, and other relevant documents. For primary sources, the study targeted policy-makers, program managers and implementers from relevant government institutions. At the local level, the local executives (Mayor and Barangay/village chairman), the Sanggunian Bayan officials (local council), and kagawads (barangay/vaillage councilors) were interviewed. Heads of the local health units, social welfare and development, teachers and local NGO's including faith-based organizations participated in the study.

\section{Procedures}

An initial meeting with an ad hoc Advisory Committee was convened to evaluate and make suggestions about the intended plan to develop a national child maltreatment prevention plan. The Advisory Body offered advice on the research work-plan; identified sources of information and programs that would benefit the research; and determined the interagency body to coordinate the national primary prevention plan.

National and local stakeholders were contacted for possible interviews and other data-collection activities. In particular, relevant documents from the national and local offices of the Department of Health, Department of Social Welfare and Development, Department of Education, and Department of Justice were reviewed. The heads of these offices and agencies or their representatives were asked to be 
interviewed. Furthermore, 3 local communities (2 urban and one rural) were selected based on their expressed interests and cooperation to participate in the study, to assess how these child maltreatment prevention programs were implemented. The views and experiences of local government officials and other influential community people were determined though focus group discussions and key informant interviews. For example, focus groups discussions with health workers, social workers and teachers as well as groups of parents were done. Individual interviews by six trained research assistants, who worked in pairs in each study site, were conducted with the mayors, barangay chairpersons, municipal health officers, school principals and head social workers.

Data-collection focused on the following:

1. Existing national and local policies and ordinances on child maltreatment, both related to prevention and protection; budget, manpower and other resources allocated for child maltreatment prevention activities;

2. Strategies, interventions, programs and other activities related to primary prevention of child maltreatment;

3. Background information on social issues relevant to child maltreatment primary prevention such as population, socio-economic issues, health, education, social services, crime and environment.

At the end of the project, local workshops were conducted to disseminate and validate the findings of the study.

\section{Results}

\section{Policies and laws on child protection}

The Philippines is one country not lacking in policies and laws related to children's protection and rights. An important law passed by Congress on June 17, 1992, Republic Act No. 7610 or the "Special Protection of Children Against Abuse, Exploitation and Discrimination Act", declares it "the policy of the State to provide special protection to children from all forms of abuse, neglect, cruelty, exploitation and discrimination and other conditions, prejudicial to their development; provide sanctions for their commission and carry out a program for prevention and deterrence of and crisis intervention in situations of child abuse, exploitation and discrimination" ${ }^{13}$ While R.A. 7610 is the Child Protection Law of the country, it remains an unfunded law. Furthermore, there are 31 laws and 17 more pending bills in Congress and a total of 93 Executive Orders, Administrative Orders, Memorandum Circulars and Board Resolutions from various government agencies. None of these laws have budgets.
Child protection programs and strategies

The first country specific plan of action for the protection and development of children was the Philippine Plan of Action for Children (PPAC) which was implemented from 1990 to 2002. The PPAC started the rights-based approach in developing plans for children. The four rights categories for all children were (1) Survival, (2) Protection, (3) Development, and (4) Participation. In 2000, Child 21 was formulated by the Council for the Welfare of Children. Immediately succeeding the PPAC, Child 21 is a strategic framework for approaching planning efforts for children. It recognized the role of the local government in determining relevant and appropriate plans and programs for their children. Aside from continuing the rights-based approach of the PPAC, Child 21 introduced the life cycle perspectives in the planning framework.

The National Plan of Action for Children (NPAC) was designed to continue the achievements of PPAC and Child 21, to update the issues and goals identified in Child 21, and to ensure that these are aligned with global policies such as the Millennium Development Goals and the World Fit for Children. The NPAC $(2005-2010)^{14}$ tried to address the budget concerns and the challenges of implementation, monitoring and evaluation. However, it still did not identify specific programs with their respective budgets. The NPAC identified the Council for the Welfare of Children (CWC) as the main agency responsible for monitoring NPAC implementation. The CWC will do this through its Macro Monitoring System and Micro Monitoring System. The two sources of data are the administrative reporting system, and the census and surveys conducted by the Philippine Statistical system.

The Special Committee for the Protection of Children, an interagency committee created by R.A. 7610 and cochaired by the Department of Justice and the Department of Social Welfare and Development, came up with the revised and updated Comprehensive Programme for Child Protection (2006-2010) ${ }^{15}$ which serves as the companion document to the NPAC. This document lists specific crosscutting strategies and interventions that should be institutionalized into existing structures at various levels and institutional settings inter alia family, school, church, media, justice system, local community, city, province and national bodies. These included primary prevention programs on child maltreatment. However, while comprehensive, they are mainly recommendatory in nature.

Another major document is the National Strategic Framework for Action to End Violence Against Children ${ }^{16}$ which is the result of the collaboration of the Council for the Welfare of Children with several government agencies, international donor organizations and NGOs (Nongovernment organizations). This Framework for Action is meant to guide the development and implementation of appropriate and effective legislative, policy and 
programmatic initiatives towards the elimination of all forms of violence against children in the Philippines. Again, this framework is recommendatory in nature.

There are many other national plans relevant to child protection and although not focused on the primary prevention of child maltreatment may serve some of the objectives of the primary prevention of child maltreatment:

\begin{tabular}{|c|}
\hline National Plans of Action \\
\hline $\begin{array}{l}\text { Strategic Plan of the Inter-Agency Council on Violence } \\
\text { Against Women and Their Children (IACVAWC) for } \\
\text { 2007-2010 }\end{array}$ \\
\hline $\begin{array}{l}\text { National Program of Action Against Child Labor and the } \\
\text { Time-Bound Program (TBP) Against the Worst Forms of } \\
\text { Child Labor }\end{array}$ \\
\hline $\begin{array}{l}\text { Philippine Plan for Gender-Responsive Development } \\
\text { 1995-2025 }\end{array}$ \\
\hline $\begin{array}{l}\text { National Plan of Action for the Youth (National Youth } \\
\text { Commission) }\end{array}$ \\
\hline $\begin{array}{l}\text { Philippine National Plan of Action to Achieve Education } \\
\text { for All by Year } 2015\end{array}$ \\
\hline $\begin{array}{l}\text { Medium-Term Youth Development Plan (MTYDP) 2005- } \\
2009\end{array}$ \\
\hline National Objectives for Health 2005-2010 \\
\hline Philippine Plan of Action for Nutrition (PPAN) 2005-2010 \\
\hline $\begin{array}{l}\text { National Policies on Infant and Young Child Feeding } \\
\text { (IYCF) } 2005\end{array}$ \\
\hline
\end{tabular}

A crucial component in the implementation of all the national plans of action for children is the Local Council for the Protection of Children (LCPC). The LCPC is tasked with the synchronization and integration of policies, programs and projects for children at the provincial, city, municipal and "barangay" (village) level. Included in the functions of the LCPC are the preparation of an annual action plan focused on children with the corresponding budget, preparation of the annual progress report on the situation of children and the monitoring of the compliance with laws and ordinances on children. At the time of the study, there was no official data on how many of these Local Council for the Protection of Children were functional.

\section{Budget allocated to child protection}

The government's budget allocation for children is usually incorporated in the budgets of various government agencies. In the 2008 budget, there was no specific budget allocated to child protection and prevention of child maltreatment in the health, education, and social welfare sectors. ${ }^{17}$ At the Department of Health, the budget allocation for children was included in the Family Health budget and imbedded in other programs that involve children across different divisions and bureaus. The same pattern has been observed from other agencies like the Department of Social Work and Development. Similar trends were also found at the city/municipal/barangay levels. Provisions for children are scattered across general programs on maternal health, nutrition, immunization, family planning. VAW (Violence Against Women), poverty alleviation, housing, livelihood and nutrition, without any formal connections, policy and practice.

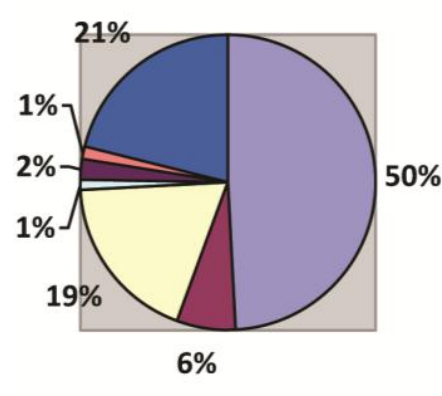

\begin{tabular}{|l|}
\hline Education, Culture, Manpower \\
Development \\
$\square$ Health \\
$\square$ Social Security, Welfare and \\
Employment \\
$\square$ Land Distribution \\
$\square$ Housing and Community \\
Development \\
$\square$ Other Social Services \\
$\square$ Subsidy to LGUs
\end{tabular}

Figure 3. Percent Share to Total National Government Budget of the Social Services Expenditure Program, 2008.

\section{Existing preventive programs}

There are current programs implemented by various government agencies and NGO's in the country which can serve as a primary prevention program for child maltreatment even if this was not the main intention of the program. Targeting the individual, there are programs on responsible parenting, maternal and neonatal health, safe motherhood and women's health, adolescent and youth health and development, breastfeeding programs, immunization programs, feeding programs, among others. At the relationship level, 20 different programs were noted that include early childhood education, parent effectiveness seminars, and bright child campaigns. At the community level, local government human rights program and day care workers competency training, and other forms of capacitybuilding programs for physicians, social workers, and teachers were reported. A Neighbourhood Early Childhood Care and Development Programs are in place. At the societal level there are efforts to pass laws that impact on changing cultural beliefs and behavior on child rearing such as the proposed anti-corporal punishment bill.

\section{Local implementation of child maltreatment programs}

Since Philippine governance of health and social services was devolved since 1991, and the implementation of government programs depends on local initiatives, it was deemed necessary to look at the child maltreatment situation at the local level. The following was the situation of child maltreatment in three local government units (LGUs).

This study involved three LGUs: two are urban areas in Metro Manila, and one is a rural municipality in the south of 
Metro Manila (For ethical reasons, the actual names of the study areas are not disclosed). All three LGUs can be considered as resource-rich, hence, they can afford to establish and maintain government programs such as those for child maltreatment prevention and protection.

\section{Urban study sites}

City A, is a large city in the National Capital Region in terms of area and population. It is composed of 142 barangays with 2.8 million residents as of 2008. Majority of the population were children aged 5-9 years. City B in the National Capital Region has about 43 percent children out of its 1.9 million population in 2008. In both cities, elementary school participation rates were adequately high although only about 60 to 75 percent of elementary graduates proceed to the secondary level.

Both cities are the center of health care as the best hospitals in the country are found in these areas. City B has 33 hospitals and 49 health centers while City A has 61 private and government hospitals with 60 health centers, including a "Teen Health Headquarters" which responds to the health concerns of the youth. City A has a higher infant mortality rate in 2008 at 31.3 per 1000 livebirths but with a lower under- 5 mortality rate of 46.9 per 100,000 population compared to City B (IMR= 23 per 1,000 livebirths, U5MR=93 per 100,000).

City B had more reported cases of child abuse than City A. It was noted that majority of City B's child abuse cases were reports coming from the Child Protection Unit located in the city and which serves as a referral center for child abuse cases. City B's Social Welfare and Development Office reported that in 2008, there were 624 cases of sexual abuse, 86 cases of physical abuse, 36 cases of psychological abuse and 97 cases of neglect or abandoned children. Moreover, about 246 children in conflict of the law were reported at the end of 2007. In City A, only about 261 cases of child abuse and neglect were reported to the Social Services and Development Office. Child Abuse data was not reported annually. The Police Department's records of City A indicated that 1,091 cases of abuse were reported from 2006 to 2009.

In terms of laws, both city governments follow the national government's policies and laws on child welfare, rights and protection. In addition, City B passed some city ordinances for the children's welfare such as: City Ordinance no. 8170, penalizing parents, guardians or persons with parental authority who allow their children to engage in vending, begging, and prostitution; City Ordinance no. 8168 which regulates the operation of computer rental shops within the city; and City Ordinance no. 8046 on barangay/village curfew hours for minors. Among the primary prevention programs were the provision of direct services to children and youth (e.g. educational assistance, socio-cultural, sports/recreational activities, character development and livelihood skills training), inclusion in the marriage counselling module session measures to prevent child maltreatment, supplemental feeding, the usual programs for maternal and child health care, immunization, nutrition and disease control. Special programs were also given to adolescents such as adolescent counselling on the prevention of drug abuse. An NGO piloted a home visiting program patterned after the Hawaii Healthy Start Program in 5 barangays/villages in City B. An evaluation was conducted with regards attitudes and beliefs of parents but not with regards prevention of child abuse nor its effect on risk and protective factors. This program was not adopted by the city and was not scaled up. Another pilot project in City B was a community-based system for family-centered care of at-risk mothers and infants in a low-income community. The pilot project was not continued due to limited resources and the lack of capacity of the local government to implement the program. Specialty services that were absent in the community such as access to Obstetric services for high-risk deliveries, child developmental assessments and intervention, were necessary for the success of the program. ${ }^{18}$

On the other hand, City A has a total of 862 ordinances and 2,912 resolutions from July 2001 to June 2009. Out of these, 14 ordinances were formulated to protect children. These ordinances include the Juvenile Intervention and Diversion Programs Ordinance, Child and Youth Welfare Ordinance - an ordinance penalizing the owner/operators of any business establishments for hiring/employing children or minors; an ordinance prohibiting the sale on retail in all sari-sari or convenient stores of the substance commonly known as "Rugby" which street children and others use as a stimulant; an ordinance prohibiting the father, mother, natural or legal guardian to use children for begging.

City A has a number of programs that were established to improve the health, education and social status of the child in general. These programs include: Maternal Health Care, Nutrition Jumpstart, Pre-Natal, Natal and Post-Natal Care, Parent Effectiveness Seminars, Childcare Development Program, Family Welfare Program, Balik- Eskwela (Back-toSchool) Program, Adopt a Pupil, Child Friendly School System, Poverty Reduction Program, Economic Development Program, Feeding Program, among others. The City Health Office or Social Services and Development Office implement these programs with the help of NGOs and international donor agencies.

The two cities are aware of the need to protect children. Both cities have many policies and programs aimed at improving the general well-being of children. However, very few leaders except those directly involved in children's programs e.g. social welfare and health, knew at least some of the different laws, policies and National Action Plans for children. The situation of the children living in these urban areas is wanting in terms of safety, health and quality of life. 
First, both cities are densely populated with large slum areas. Health professionals as well as social workers, during the interviews, complained about the large number of cases needing tertiary intervention and for which they do not have the necessary personnel and resources. Documents in City B showed that some services could only reach up to 25 percent of the actual child population.

Second, the programs on child maltreatment are tertiary services for abused children such as a hospital-based multidisciplinary child protection unit. The programs, which might be categorized as primary child maltreatment programs are the usual government programs on maternal health and basic child care services as well as anti-crime efforts by the police. These are the same programs that are endorsed and supported nationwide by the Department of Health, Department of Social Welfare and Development and Department of Education. Moreover, the general level of consciousness was more on tertiary child protection and not on primary prevention of child maltreatment.

Third, while City A provides a share of the annual budget for child-focused programs (e.g., the Child Welfare Program had 29.3 million pesos budget in 2009; the Youth Welfare Program had 4.6 million, and the Family Welfare Program had 37.3 million), whether these monies were actually spent as intended was not clear from the records and interviews. In City B, local interviews revealed that only one percent of the barangay/village budget was allocated to the Local Council for the Protection of Children (LCPC). This amounts to a very small budget of Php12,000 a year.

Fourth, not all the programs and services enumerated earlier are available at the barangay/grassroots level. Many community informants were not aware that such programs exist. There was also the problem of record keeping which made it difficult to monitor the effectiveness and reach of the different programs. In cases where statistics were provided to the city officials, it was only as a means of requesting for funds for specific programs at the barangay/village level.

Finally, there has been no evaluation of the quality and effectiveness of these programs to prevent child maltreatment even if there are resources to scale up effective programs.

\section{Rural study site}

Municipality $\mathrm{C}$ is a rural area that is located in the Southern Tagalog region of the Philippines. As of 2001, it had a total population of 79,482 with almost equal ratio of males and females. It had a child population of 39,604 where majority were aged 5-9 years. The average number of children in the household was 2.73 .

All barangays/villages in Municipality $C$ have at least one Day Care Center that caters to children aged 4 years. The 42 barangays/villages had a total of 46 day care centers which are usually managed by volunteer elementary school teachers. Most of these children are enrolled in kindergarten once they are 5 years old.

In terms of health and social services, the local Social Welfare and Development Office offered services that included Self-Employment Assistance Program, Youth Welfare Development, Women's Welfare Program, and Day Care Services Program. The Health Centers implemented such programs as the Expanded Program on Immunization, Maternal and Child Health Services, Family Planning, Adequate Food and Proper Nutrition, Environmental Sanitation, Care of Acute Respiratory Illness, Control of Diarrheal Diseases, Provision of Essential Drugs and health education. A Women and Children`s desk was present in the police station of Municipality C.

The 2007 infant mortality rate was 5.57 per 1000 livebirths while the 2006 child mortality rate was $0.17 / 1000$ live births. Infant deaths were mostly due to stillbirth, prematurity, pneumonia and sepsis. Child mortality was mostly attributed to severe malnutrition, pneumonia, and sepsis. Full immunization rate for infants $0-12$ months was $89.6 \%$ in 2007.

The leaders of the municipality were unaware of the national laws, policies and National Plans of action for children. While there were no services primarily for the prevention of child maltreatment, the community had some resources to help parents and youth. There was a youth organization, "Alagaan Natin Ang Kabataan (ANAK)", with an annual budget of P50,000 allotted for its programs (e.g., sports for out-of-school youth). There were also parent organizations such as the Parent-Teachers Association; INA ("Ilaw Nayon Asosasyon") - a federation of mothers, which conducts livelihood and skills' training programs; and AMA (Aksyon Mindanao Asosasyon), an organization of fathers. The local Social Welfare and Development Office ran parenting classes (Parent Effectiveness Seminar) and a feeding program.

In 2008, a budget of $\mathrm{P} 3,435,600$ was allotted for the day care program services. The Municipal Social and Development Office had 9 regular employees and 2 volunteers, providing generic social welfare services. There were no specialized child protection services.

There were no data on child maltreatment in any agency in Municipality C. The Chief of Police during the interview only mentioned that there were discreet activities of prostitution and child trafficking in the beach areas at the peak of the tourist season. No street children or homeless families were seen during the time of data-collection.There was no specific child maltreatment program. Child maltreatment was not considered a problem and majority of the members of the community believed that corporal punishment is acceptable and good for children. Those interviewed in Municipality $\mathrm{C}$ gave the impression that the children's general well-being in the town was quite satisfactory. However, there were some apprehensions that 
the town's growing tourist industry will lead to delinquent behavior by its youth and bring in new undesirable elements.

\section{Discussion}

This study shows that the Philippines is a country with the necessary legal framework for the prevention of child maltreatment but has insufficient political will and resources to implement it. It is remarkable that almost all of the laws on child protection are unfunded. There is a wide range of knowledge, attitudes and beliefs on the prevention of child maltreatment by both political leaders and the general public. They range from recognizing child maltreatment as a problem and piloting some primary prevention programs as seen in City B to denial that there is a problem as shown in Municipality C. City A, on the other hand, looks at standard health, education and social services as primary prevention efforts against child maltreatment. There is not much understanding of primary prevention of child maltreatment. Most of the pilot projects on the primary prevention of child maltreatment had been done by NGOs and are not adopted by the local government once funding had ran out. Child protection is mainly seen as the responsibility of the Department of Social Welfare and Services. The main concern of local leaders is still the delivery of basic services including clean water and sanitation.

There are no data on child maltreatment at the local level and there is no attempt to connect to a national database. The data that are collected are the generic education, health, social welfare and crime data. Most of the time, these data are not disaggregated by age and gender. The child maltreatment statistics are based on reports that do not reflect the true prevalence of the problem. It is difficult to gauge the success or lack of success of interventions without any reliable data. In all the areas, collection of data at the barangay/village level is poor. If there are any data at all, it is handwritten in log books and not collated and reported. Majority of the programs had no data on the percentage of the target population reached. Programs are not evaluated as to effectiveness.

While there are National Plans of Action for children including a Framework to End Violence against Children, there is no central agency with the mandate to ensure its implementation. Instead, there are many interagency committees created by special laws to oversee the implementation of specific laws protecting special categories of children e.g. Special Committee for the Protection of Children, Interagency Committee against the Trafficking of Persons, Juvenile Justice and Welfare Council. These committees are based in Metro Manila and rarely have a presence in the provinces. While the primary prevention of child maltreatment cuts across all sectors, most of the recognized programs that were enumerated by the participants of this study belong to either health or social welfare. Both of these national agencies are devolved agencies and as such the implementation of health and social welfare services are mainly through local governments. Unfortunately, the different national plans of actions for children and the framework for the prevention of violence against children are largely not known to the local leaders and the members of the community.

It is interesting to note that the two pilot programs in City B that may be considered as programs on the primary prevention of child maltreatment were not continued by the local government. The main reasons cited were limited resources and lack of capacity. The local leaders did not consider them as priority programs.

\section{Recommendations}

1. There is a glaring lack of data with regards child maltreatment in the Philippines. A prevalence study with regards the burden of the problem will help convince both political leaders and the general public the urgency of the problem. This will also help in advocating for the funding of the child protection laws.

2. There are evidence-based programs on the primary prevention of child maltreatment but the majority of the research had been done in high income countries. Some of these programs can be adapted to the Philippine setting and evaluated for their effectiveness taking into consideration local context such as readiness and capacity to implement primary prevention programs. It may mean doing the work by stages; working to increase the community's capacity and readiness until it is able to implement the program.

3. A central government body needs to be identified who will be responsible for the implementation of the Framework to End Violence against Children and should be given the legal mandate and the resources to do so. The Framework needs to be revisited to come up with an action plan which identifies the agency responsible (whether government or non-government), specific actions, responsibilities and timeframes for implementation. The Framework should go beyond just recommendations. It should be a binding instrument.

4. Dissemination of information on the child protection laws, policies, National Plan of Action for Children, the Comprehensive Program on Child Protection, the Framework to End Violence Against Children should be done nationwide with special attention given to the local leaders. 


\section{Acknowledgments}

We would like to thank the support and financial assistance provided by the World Health Organization through its Department of Injury and Violence Prevention and the World Health Organization, Philippines. To our research assistants: Marrion Dabalos, Annabelle Lo-Ayos, Shiela E. Basio, Shyrel P. Valenzuela, Kristine Tanega-Aliling, Maria Carla A. Madson, Angeli Espiritu, Janelle Margaux Logronio, and Loudella V. Calotes-Castillo. Our many thanks to all our study participants: heads of offices, local government officials and implementors of programs.

\section{References}

1. Ricardo R. Child Trafficking in the Philippines: A Situational Analysis. Manila: International Labour Organization-International Programme on the Elimination of Child Labour, 2007.

2. Department of Health. Baseline Survey for the National Objectives for Health (BSNOH). Manila, Philippines, 2000.

3. Republic of the Philippines National Statistics Office. Philippines: National Statistics Office. The number of working children 5 to 17 years old is estimated at 5.5 million (Preliminary Results of the 2011 Survey on Children) [Online]. 2012 Jul 18 [cited 2013 Jan]. Available from http://www.census.gov.ph/content/number-working-children-5-17years-old-estimated-55-million-preliminary-results-2011-survey.

4. Child Protection Network Foundation, Inc. Annual Report 2009. A profile of the children seen at the 31 CPUs in 2009, p 8 .

5. Krug EG, Dahlberg LL, Mercy JA, Zwi AB, Lozano R, eds. World report on violence and health. Geneva: World Health Organization; Chapter 1, pp. 3-4. Violence - A Global Public Health Problem [Online]. 2002 [cited 2012 Dec]. Available from http://www.who.int/ violence_injury_prevention/violence/world_report/en/chap1.pdf

6. Pinheiro P. United Nations Secretary-General's Report on Violence against Children. Part VI, Recommendations, p. 99. [Online]. [cited 2012 Dec]. Available from http://www.unicef.org/violencestudy/ reports/SG_violencestudy_en.pdf

7. MacMillan HL, Wathen C, Barlow J, Fergusson DM, Leventhal JM, Taussig HN. Interventions to prevent child maltreatment and associated impairment. Lancet. 2009; 373(9659):250-66.

8. Butchart A, Phinney A, Check P, Villaveces A. Preventing violence: A guide to implementing the recommendations of the World report on violence and health [Internet]. Geneva: Department of Injuries and Violence Prevention, World Health Organization, Part 3, Promoting the primary prevention of interpersonal vilolence, pp. 3346. [Online]. 2004 [cited 2012 Dec]; Available from http://whqlibdoc.who.int/publications/2004/9241592079.pdf

9. Kilburn MR, Karoly LA. The Economics of Early Childhood Policy: What the Dismal Science Has to Say About Investing in Children. Santa Monica, CA: RAND Corporation [Online]. 2008 [cited 2012 Dec]. Available from http://www.rand.org/content/dam/rand/pubs/ occasional_papers/2008/RAND_OP227.pdf

10. Mikton C, Butchart A. A systematic review of child maltreatment prevention reviews: mapping the evidence. Bulletin of the World Health Organization, 87(5),325-404. [Online]. 2009 Feb 1 [cited 2012 Dec]. Available from http://www.who.int/bulletin/volumes/87/5/08057075/en/index.html

11. The Bangkok Charter for Health Promotion in a Globalized World. Health Promot Int. 21(suppl 1):10-14. [Online]. 2006 Dec [cited 2012 Dec]. Available from http://heapro.oxfordjournals.org/ content/21/suppl_1/10.long

12. Plested B, Edwards R, Jumper-Thurman P. Community Readiness: A Handbook for Successful Change. Fort Collins,CO: Tri-Ethnic Center for Prevention Research, 2006.

13. An Act Providing for Stronger Deterrence and Special Protection Against Child Abuse, Exploitation and Discrimination, and for Other Purposes, R.A. No. 7610, $9^{\text {th }}$ Cong, June 17, 1992.
14. Council for the Welfare of Children The Filipino Child of the Millennium: National Plan of Action for Children 2005-2010. [Online]. 2006 [cited 2009 Dec]. Available from http://www.cwc.gov.ph

15. Special Committee for the Protection of Children. Protection Filipino Children from Abuse, Exploitation and Violence: A Comprehensive Programme on Child Protection, 2006-2010. Building a Protective and Caring Environment for Filipino Children. Department of Justice, Padre Faura, Manila.

16. Council for the Welfare of Children. National Framework for Action to End Violence Against Children. CWC, Quezon City, 2006.

17. Congressional Planning and Budget Department. An Analysis of the President's Budget for Fiscal Year 2008: The Social Payback Dimension. Quezon City: House of Representatives; 2007 Nov. Table 4.5 Social Services Expenditure Program, 2006-2008 [Online]. [cited 2012 Dec.]. Available from http://www.congress.gov.ph/download/ cpbd/2008_budget_analysis.pdf

18. Reyes A. Bagong Bantay Program: I-CATCH Philippines [Online]. 2011 Jun 1 [cited 2011 Jun]. Available from http://www.pediatricnews.com/index.php?id=7791\&cHash=071010\&tx_t tnews[tt_news] $=78370$. 